\title{
Modeling Molecular Interactions of Sodium Montmorillonite Clay with 3D Kerogen Models
}

\author{
Dinesh R. Katti*, Keshab B. Thapa, Kalpana S. Katti, \\ Department of Civil and Environmental Engineering, \\ North Dakota State University, Fargo ND 58105
}

*Corresponding author: Dinesh.Katti@ndsu.edu, Ph: 701-231-7245, Fax: 701-231-6185 


\begin{abstract}
The interactions of kerogen with charged mineral entities such as clays in oil shale are important for the development of new processes for extraction of kerogen from oil shales. In this work, the complex 3D structure of Green River Type, I kerogen was developed from its seven components or fragments using Siskin's two-dimensional (2D) structure. Sodium (Na)-montmorillonite, one of the minerals identified in the Green River oil shale, was chosen for kerogen and clay mineral interaction study. The seven fragments of the kerogen structure vary in complexity with moities ranging from aliphatic, aromatic and olefinic hydrocarbons to nitrogenous aromatic, aliphatic and ammonical structures. The molecular orientation of each fragment was evaluated using Molecular dynamics (MD) simulations indicating significant non-bonded interactions between clay and kerogen. The simulation results also illustrate the significant non-bonded interactions of Na-montmorillonite clay preferentially with fragments 4, 5, 6, and 7 as compared to fragments 1 , 2 , and 3. The quantitative values of interactions were compared in the context of the molecular nature and differences between the fragments. These interactions were primarily predominated by van der Waals energy. Also, fragment 7 has the highest interaction with clay. At the same time, when kerogen interacts with clay minerals, there were also strong attractive non-bonded interactions between the kerogen fragments. Fragments 5 and 7 and fragments 6 and 7 have higher interactions between them than other fragments. These interactions were primarily electrostatic in nature. These studies represent a comprehensive analysis of the interactions of the complex 3D structure of kerogen with montmorillonite. The interactions between kerogen and clay mineral and within kerogen fragments provide insight for researchers to develop new methodologies to extract the kerogen economically, efficiently, and environmentally friendly from Green River oil shale.
\end{abstract}

\title{
Keywords
}

- Oil Shale

- Kerogen

- Na-montmorillonite

- Molecular Dynamics 


\section{Introduction}

Energy demands of the world continue to increase and thus increase the oil demand worldwide. Overreliance on conventional sources of energy can cause the instability of supply and demand in the future. The fluctuation of oil price over the years has also led researchers to seek to develop unconventional sources of energy. Thus, oil shale is an integral and alternative source of energy. The Green River Formation is situated in the Western United States in Colorado, Utah, and Wyoming and it has $70 \%$ of the total oil shale reserves in the world [1]. These regions have about 1.5 trillion barrels of oil with estimated recoverable oil of 800 billion barrels [2], which is three times greater than the reserves of oil in Saudi Arabia [3].

Oil shale is a fine-grained sedimentary rock that is formed by the deposition of clay and other mineral particles and organic matter. The organic matter in oil shale consists of bitumen and kerogen. Kerogen is the most abundant form of combustible carbonaceous material on earth, which is a precursor of crude oil and insoluble in common organic solvents [4]. Kerogen contains hydrogen, oxygen, carbon, nitrogen, and sulfur. The classification of kerogen as Type I, Type II, and Type III depends on the hydrogen, carbon, and oxygen content [5]. Green River oil shale belongs to Type I kerogen because the hydrogen to carbon ratio is greater than 1.25 and oxygen to carbon ratio is less than 0.15 [6]. Green River oil shale contains $86.2 \%$ mineral matter and $13.80 \%$ organic matter by weight percentage [7]. The minerals primarily consist of dolomite, calcite, montmorillonite, feldspar, and quartz. Mineral content within kerogen plays a significant role during kerogen formation in oil shale, and clay minerals act as catalysts and restrain the organic matter [8,9]. Oil shale yields a significant amount of oil through pyrolysis or retorting; heating of oil shale under varied temperature produces oil [10], [11]. The pyrolysis of oil shale using a wide range of acids produces a significant amount of oil because self-heating temperature assists to cleave the various hydrocarbon chains [1]. Simulation of pyrolysis using molecular dynamics showed the breakdown of $\mathrm{C}-\mathrm{C}$ bonds, resulting in the formation of small molecules of aliphatic hydrocarbons [12]. However, pyrolysis involves excessive energy to decompose kerogen and mineral matrix to shale oil and produces toxic compounds, and is thus commercially uneconomical [13]. 
Molecular dynamics simulation is an excellent computational tool to understand the behavior of materials at a molecular level. In our previous work, extensive studies have been carried out to investigate the mechanical response of clay as well as interactions between clay and fluids by Fourier transform infrared (FTIR) spectroscopy and molecular dynamics simulations [14-19]. It has been observed that the configuration of fluid molecules in the clay layer during swelling is influenced by non-bonded interactions between them [20]. In our prior work, molecular interaction of the composite system has been studied [21, 22]; the mechanics of organic structures was found to be influenced by the mineral proximity and non-bonded interaction between organics and minerals [23-25]. Furthermore, we studied these phenomena using molecular dynamics simulations in various bio-nanocomposites: seashell [23], bone [26], polymer clay nanocomposites [21], and polymeric hydroxyapatite nanocomposites [27].

Extensive photoacoustic FTIR experiments on insitu Green River oil shale have been performed in our previous work [3]. We have observed that the significant molecular interactions between kerogen and minerals in oil shale, were primarily non-bonded interactions. The nanomechanical behavior of oil shale has been studied, and the modulus of kerogen was found to be in the range of 5-11 GPa [28, 29]. Kerogen is amorphous and finely dispersed on the minerals with a size in the order of tens of nanometers [29]. Although the structure of kerogen is complex, kerogen moieties in Green River oil shale have been identified [30], and the interactions with minerals have been studied [31]. Montmorillonite, one of the minerals in Green River oil shale, is an expansive clay mineral in swelling clay used as landfill liners, asphalt modifier, drug delivery system, and polymer clay nanocomposites. Also, molecular dynamics and FTIR studies were carried out to investigate the molecular interactions between Na-montmorillonite and three specific kerogen moieties: pyridine, heptylamine, and quinaldine [32]. The results indicated that strong non-bonded interactions exist between Na-montmorillonite and the kerogen moieties. The extraction and mechanism of these kerogen moieties from the silica surface have also been studied using molecular dynamics simulation [33].

The functional group of kerogen exposed to mineral surface illustrates the binding of kerogen with mineral matrix owing to non-bonded interactions [6]. Different methods have been applied to separate unaltered kerogen from the mineral matrix in oil shales, but an efficient method of kerogen extraction from oil shale remains elusive [34]. Thus, molecular modeling analysis of 
three-dimensional (3D) kerogen and mineral is a promising aid to extract kerogen effectively. The representative two-dimensional (2D) kerogen structure of Green River oil shale has been developed by Siskin using mass spectroscopy and NMR analysis [35]. Based on Siskin's 2D structure, 3D Green River Kerogen model was developed by ab initio and molecular mechanics computations [36]. Although the fundamental 3D kerogen structure was initially obtained [37] using a computational tool, molecular dynamics simulations have not been conducted yet. In our study, the molecular model of 3D of Green River Kerogen was developed to mimic the natural kerogen structure using 2D Siskin structure, and CHARMm compatible force field parameters. Nevertheless, the non-bonded interactions energy between 3D kerogen and mineral have not been investigated by molecular dynamics simulations. These non-bonded interactions are essential to design the methodologies to extract the oil, efficiently, economically, and environmentally safe from oil shale. In this study, we present our results from molecular dynamics simulation on Green River type I kerogen and Na-montmorillonite clay mineral and insight into conformation and quantitative non-bonded interactions of kerogen in proximity to the clay mineral at the molecular level.

\section{Methodology}

\subsection{Model construction}

The Na-montmorillonite clay sample (SWy-2) was acquired from the Clay Minerals Repository at The University of Missouri, Columbia, Missouri with the chemical formula of the unit cell of this mineral as $\mathrm{NaSi}_{16}\left(\mathrm{Al}_{6} \mathrm{FeMg}\right) \mathrm{O}_{20}(\mathrm{OH})_{4}$. The coordinates of the unit cell were obtained from the model proposed by Skipper et al. [38] and the atomic charges were used as described in the work by Teppen et al. [39]. The $4 \times 2$ model was initially constructed for studying the mechanical response of both dry and hydrated sodium montmorillonite clay [40]. The Na-montmorillonite clay layer has a tetrahedral-octahedral-tetrahedral (T-O-T) structure. An octahedral clay sheet was sandwiched between tetrahedral clay sheets. The dimensions of the unit cell used were $5.28 \AA$ x $9.14 \AA$ x $6.56 \AA$. However, in our work, each clay model developed was $6 \times 3$ unit cells, with 6 unit cells in X-direction and 3 unit cells in Y-direction and overall initial dimensions of $31.68 \AA$ x $27.44 \AA$ x $24.16 \AA$ as shown in Fig. 1. The isomer substitution by metal atoms has taken place in the octahedral sheet, resulting in the negative charge on the individual clay sheets. During isomer substitution, nine Aluminum $\left(\mathrm{Al}^{3+}\right)$ cations were replaced by nine Iron $\left(\mathrm{Fe}^{3+}\right)$ 
cations and another nine Aluminum $\left(\mathrm{Al}^{3+}\right)$ cations by Magnesium $\left(\mathrm{Mg}^{2+}\right)$ cations. The negative charges of the clay sheets were balanced by adding nine sodium $\left(\mathrm{Na}^{+}\right)$cations (naturally found inorganic species in the clays) in the interlayer. The detailed explanation of $6 \times 3$ model construction was described in our previous work [41].

The construction of a complete 3D kerogen model was initiated based on the Siskin's 2D kerogen structure. The chemical formula of Green River Type I kerogen is $\mathrm{C}_{645} \mathrm{H}_{1017} \mathrm{~N}_{19} \mathrm{O}_{17} \mathrm{~S}_{4}$ [35]. In this work, the parameters and structures were constructed by dividing kerogen into seven fragments: fragment $1\left(\mathrm{C}_{18} \mathrm{H}_{38}\right)$, fragment $2\left(\mathrm{C}_{18} \mathrm{H}_{30}\right)$, fragment $3\left(\mathrm{C}_{20} \mathrm{H}_{42}\right)$, fragment $4\left(\mathrm{C}_{45} \mathrm{H}_{60} \mathrm{O}\right)$, fragment $5\left(\mathrm{C}_{75} \mathrm{H}_{117} \mathrm{~N}_{4} \mathrm{O}_{5}\right)$, fragment $6\left(\mathrm{C}_{102} \mathrm{H}_{167} \mathrm{NOS}_{2}\right)$, and fragment $7\left(\mathrm{C}_{367} \mathrm{H}_{547} \mathrm{~N}_{10} \mathrm{O}_{10} \mathrm{~S}_{2}\right)$. The complex kerogen molecule was considered as an agglomerate of these seven fragments. The fragments were known to entangle with each other through molecular interactions to form the complete kerogen complex structure. Fragments 1, 2 and 3 as described were similar, with 18, 12 and 20 aliphatic hydrocarbons respectively, and 0,6 and 0 aromatic hydrocarbons respectively. They were also similar in size, with 56, 48 and 62 atoms respectively. Fragment 4 also consisted of 18 aromatic hydrocarbons and also contained 2 olefinic hydrocarbon and was the larger sized fragment with 106 atoms. Fragment 5 consisted of 16 Aromatic Hydrocarbons and also contains 2 aromatic nitrogens, 2 olefinic hydrocarbons, 2 aliphatic nitrogens, and 1 ammonical nitrogen and was thus a larger fragment with 201 atoms. Fragments 6 was also large with 273 atoms and contained 20 aromatic hydrocarbons, 2 olefinic hydrocarbons, and 1 aliphatic nitrogen. Overall, fragment 7 was found to be the largest with 926 atoms and was also the most complex with 94 aromatic hydrocarbons, 7 aromatic nitrogen, 24 olefinic hydrocarbons, 3 aliphatic nitrogens, and 3 ammonical nitrogens. The construction of the complete kerogen 3D structure was developed starting from fragment 1 to fragment 7 (Fig. 2). Materials Studio 6.0 software was used to build all the models. The coordinate file of these models was acquired from Material Studio in protein data bank (pdb) format, and structure file was obtained from Visual Molecular Dynamics (VMD) 1.9.1 plugin in protein structure file ( $\mathrm{psf}$ ) format. These individual fragments were then merged into a single model using Visual Molecular Dynamics (VMD) Merge Structures plugin. The CHARMm force field parameters for small organic molecules have been developed using CHARMm General Force Field (CGenFF) [42]. CHARMm compatible force field parameters were obtained for the structures using ParamChem - a web-based integrated cyber environment developed by multi-disciplinary team collaborating between the members of the research groups 
from various University Institutions. The CHARMm force field parameters were generated by analogy by CGenFF program. CGenFF is a program for assigning atom type parameters and charges by analogy method in an automated manner. The complete fragment 7 (largest) structure was built by splitting the fragment 7 into five smaller parts since due to the limitation on the number of atoms that can be used to generate the force field parameters in a molecule using ParamChem. These fragments were then merged to construct a single 3D kerogen molecule as shown in Fig. 3. In order to built a realistic model, the 12-unit 3D kerogen model was constructed by merging twelve single 3D kerogen molecules using VMD Merge Structures plugin. From our previous studies, extensive experimental results have shown that the dimension of kerogen locked in oil shale is of the scale of tens of nanometers [29]. Therefore, overall dimensions of the 12-Unit 3D kerogen model used were $\mathrm{X}=71.92 \AA, \mathrm{Y}=88.98 \AA$, and $\mathrm{Z}=63.89 \AA$ which is also consistent with the experimental result (Fig. 4).

Further, the 12-unit 3D kerogen model was subjected to the same in situ stresses that were experienced by the materials during the geologic formation of the kerogen to create an in situ kerogen molecular model. The kerogen model was brought in the proximity of one of the significant minerals, Na-montmorillonite clay, identified in the Green River oil shale. Further, 12-unit 3D kerogen model was inserted between two 6x3 unit Na-montmorillonite clay models using VMD Merge Structures plugin, resulting in the development of the representative kerogenmineral model. Overall dimensions were found to be $X=71.92 \AA, Y=88.98 \AA$, and $Z=105.89 \AA$ (Fig. 5).

\subsection{Simulation details}

Molecular dynamics was used for the molecular modeling of 12-unit 3D kerogen model and Namontmorillonite clay. In molecular dynamics (MD), NAMD 2.9 developed by Theoretical and Computational Biophysics Group, Beckman Institute, the University of Illinois at UrbanaChampaign, was used. When the construction of a single unit of 3D kerogen molecule model was developed, the next task was to make the molecular cluster of kerogen molecules to mimic real conditions. For this purpose, twelve single 3D-kerogen molecules were combined. The 12unit 3D model was minimized and run through annealing cycles to assure that the confirmation of molecule was the true confirmation and free from artifacts during molecule building process. In minimization, the temperature was $0 \mathrm{~K}$, and pressure was 0 atmosphere. After minimization, an annealing process was carried out, which involved optimization of the large and complex 
system [43]. Temperature was slowly decreased in the annealing process, and molecules get sufficient time to redistribute their position [44]. In the first step, the simulations were run at normal room temperature and atmospheric pressure (NTP), resulting in isothermal-isobaric conditions. The temperature was increased from $0 \mathrm{~K}$ to $300 \mathrm{~K}$ in three steps with an increment of $100 \mathrm{~K}$. The pressure was increased from 0 atmosphere to 1 atmosphere (1.013 bars), keeping the temperature constant at $300 \mathrm{~K}$. However, the pressure was raised in four steps with 0.25 bar increments. The second step of the simulation was to increase the temperature of the 12-unit 3D kerogen model from $300 \mathrm{~K}$ to $500 \mathrm{~K}$ with an increment of $100 \mathrm{~K}$. In the final step, the model was cooled from $500 \mathrm{~K}$ to $300 \mathrm{~K}$ at $100 \mathrm{~K}$ steps. The final simulation was done for 2,000,000 steps with a time step of $0.5 \mathrm{fs}$, and simulation period of $5 \mathrm{~ns}$. The energy vs time for a typical simulation is shown in Fig. 6, which validates equilibration of the system. All simulations were run using Thunder Cluster with two nodes and 20 processors at the Center for Computationally Assisted Science and Technology (CCAST) at North Dakota State University, Fargo, North Dakota.

The representative model of $6 \times 3$ Unit Na-montmorillonite was acquired by comparing $d$-spacing simulation result of the clay sheet with X-Ray diffraction (XRD) result. The simulation was run for 800,000 steps with the time step of $0.5 \mathrm{fs}$, which is equivalent to $400 \mathrm{ps}$. The periodic boundary conditions were applied to models to imitate the infinite number of clay sheets separated by an interlayer. The clay sheets were constrained in $\mathrm{X}$ and $\mathrm{Y}$ direction but allowed to move in the $\mathrm{Z}$ direction. On the other hand, 12-unit 3D kerogen model is allowed to move in all directions. The 12-unit 3D kerogen and the Na-montmorillonite model was also run for $400 \mathrm{ps}$ at NTP. Additionally, the model was run for five ns in 15 steps after NTP to ensure the simulation was stable for a longer duration.

\section{Results and discussion}

For the representative model of Na- montmorillonite, the d-spacing was measured by computing the vertical distance between the corresponding surface oxygen atoms of the clay sheets molecular model of the Na-montmorillonite after MD simulation is shown in Fig. 7. The experimentally obtained d-spacing of dry Na- montmorillonite was $9.85 \AA$ [14], and our molecular dynamics simulation computed d-spacing of $10.72 \AA$. Thus, due to the closeness of the $d$ pacing calculation to experimental, this model was used in further simulations. Since the 
clay model used in the study was small, periodic boundary condition was used to replicate this structure to form infinite clay sheets parallel to each other.

Fig. 8 shows the equilibrated 12-unit 3D kerogen model after annealing process for time period of $1 \mathrm{~ns}$. The atomic pair distribution functions (PDFs) analysis was conducted on the 12-unit 3D kerogen to validate the kerogen modeling system. A PDF plot was developed, as seen in Fig. 9, using VMD-Radial Pair Distribution Function plugin, and results were compared with the radial distributions from NMR experiment and a computational model from literature [36] on kerogen from the Green River oil shale. The atom-atom correlations agree with results from Orendt et al. [36] based on typical carbon bond lengths, $\mathrm{C}-\mathrm{H}(1.15 \AA)$ and $\mathrm{C}-\mathrm{C}(1.55 \AA)$, angles, $\mathrm{C}-\mathrm{C}-\mathrm{H}$ $(2.15 \AA)$ and $\mathrm{C}-\mathrm{C}-\mathrm{C}(2.55 \AA)$, and dihedrals, $\mathrm{C}-\mathrm{C}-\mathrm{C}-\mathrm{C}(3.85 \AA)$. The distributions were also found to be consistent with results from NMR data presented by the same authors. These results suggest that the newly constructed 12-unit 3D kerogen model was a viable, representative kerogen model for incorporation into kerogen-mineral interaction studies.

A snapshot of the 12-unit 3D kerogen and 6x3 unit clay model after the simulation duration of 5 ns is shown in Fig. 10. The overall dimension of the model is $x=65.42 \AA, y=86.62 \AA$, and $\mathrm{z}=99.70 \AA$, which is still on the order of tens of nanometer size and smaller than the initial dimension of the model. The conformation of kerogen was observed to be changed in the presence of clay mineral. The kerogen pulled the clay sheet by $11 \AA$ in z-direction which supports the strong attractive non-bonded interaction between them. The snapshots of kerogen fragment 1 through fragment 7 with clay sheets after the MD simulations are shown in Fig. 11 and Fig. 12. The total non-bonded interaction between clay and the individual seven fragments of 12-unit kerogen was computed. Due to isomeric substitution, negative charges were developed in the clay sheets, and the hydrogen atoms of the kerogen that were present in all the fragments were attracted by the clay sheet. The non-bonded interaction becomes weak when the distance between the kerogen and clay sheets exceeds $12 \AA$, the region within this distance is considered in proximity to clay sheet in this study. Overall the resulting interactions were strong because a large number of atoms have been included in the interaction.

The conformation of kerogen fragments in clay mineral provides insight about the trapped kerogen within the mineral matrix. In this work, the orientation of individual fragments at the molecular level was studied. There were 12 of each of the seven fragments in the 12-unit 3D 
kerogen model. However, only certain numbers of each fragment, as seen in Fig. 11(a-f) and Fig. 12, were in proximity to clay sheets: fragment 1 had two, fragment 2 had five, fragment 3 had three, fragment 4 had three, fragment 5 had three, fragment 6 had three, and fragment 7 had four. In the case of fragment 1 , which mainly consists of aliphatic hydrocarbons, one of the fragment units was aligned parallel and perpendicular to the clay surface in the XY-plane as shown in Fig. 11(a). The aromatic hydrocarbons of fragment 2, on the other hand, were more influenced and attracted to the clay sheet than its aliphatic hydrocarbons, as seen in Fig. 11(b). It was evident that the aliphatic hydrocarbons of fragment 3 and aromatic hydrocarbons of fragment 4 were flat and parallel to the surface of the clay sheet as shown in Fig 11(c) and Fig. 11(d) respectively. Fig. 11(e-f) shows the aliphatic and aromatic hydrocarbons of the fragments 5 and six were shifted toward the clay sheet. Most of the aromatic hydrocarbons were perpendicular, and aliphatic hydrocarbons were parallel to the clay surface in fragment 5 . In contrast, the aromatic hydrocarbons of fragment 6 were perpendicular to the clay surface. Fragment 7 was the largest fragment, and it contains a higher number of atoms than other fragments. It was found that the aliphatic hydrocarbons, aromatic hydrocarbons, and aromatic nitrogen were oriented toward clay surface as shown in Fig. 12. Aliphatic hydrocarbons were flat and randomly oriented, but aromatic hydrocarbons were normal to the clay surface. Aromatic nitrogens were flat, parallel, and inclined to the clay surface. This study shows that the edges of the functional groups of these fragments were pointed towards the clay sheet because the oxygen atoms lying on the surface of clay sheets possess high negative charge.

Kerogen-mineral interaction was studied in our previous work by photoacoustic FTIR on the Green River Oil Shale [3]. The result showed that the kerogen-clay interaction is mainly nonbonded in nature. Thus, in this work, the non-bonded energies between kerogen and clay and between kerogen fragments have been computed. The non-bonded energy is the summation of electrostatic energy and van der Waals (VDW) energy. The attractive and repulsive energies between the two constituents of the modeling system were represented by the negative and positive energies respectively. Fig. 13 shows the interaction energy between 12-unti kerogen and clay, to be strong attractive non-bonded interaction. These results were consistent with our previous studies on the Green River oil shale [3]. The VDW energy between kerogen and clay sheets was very high, and it was $290 \%$ higher than electrostatic energy. However, the interaction energy between kerogen and sodium was small compared to kerogen-clay interaction. The 
nonbonded interactions between sodium $(\mathrm{Na})$ and clay sheets before and after the introduction of kerogen is shown in Fig. 14.

The computation of energies was carried out by considering kerogen fragments in proximity to clay surface only. Fig. 15 shows that fragments 4 through 7 have higher non-bonded interactions with clay than other fragments, and these attractive interactions were predominated by VDW energy. VDW energy was found to be almost the same for fragments 1 and 2, resulting in same total non-bonded energy. However, VDW energy between fragment 3 and clay sheet was 250\% greater than fragments 1 and 2 and clay. Similarly, VDW energy of fragment 4 and clay was more than 200\% greater than fragment 3 and clay. The total non-bonded energy of fragment 4 with clay was slightly greater than fragment 5 with clay whereas the corresponding electrostatic interaction energy was similar. The non-bonded energy between fragment 7 and clay was observed to be more than $250 \%$ greater than that between fragment 6 and clay. Although the VDW energy was $300 \%$ greater, in this case, electrostatic energy remained the same. Thus, our molecular dynamics studies show a significant non-bonded interaction between kerogen fragments and clay. Among the seven fragments, fragment 7 exhibited the highest non-bonded interaction with clay. These results also suggest that the VDW interactions play a significant role in kerogen-mineral interfaces.

At the same time when kerogen interacted with clay, strong molecular interactions between kerogen fragments were observed. Fig. 16 shows the variation of interaction energy between kerogen fragments, fragments 4 through fragment 7 . These interactions were attractive in nature and increased with increasing fragments from 4 to 7 . The interactions within kerogen fragments arose due to both VDW and electrostatic interactions. All the interactions were primarily attractive in nature. Although the total non-bonded interaction between fragments 4 and 5 and fragments 4 and 7 was approximately the same, interaction energy between fragments 4 and 6 was slightly greater than fragments 4 and 7 . On the other hand, the total non-bonded interaction between fragments 5 and 6 was about 350\% higher than fragments 4 and 7. These interactions were VDW in nature. The non-bonded interaction between fragments 5 and 7 was more than $150 \%$ greater than fragments 5 and 6. Fig. 16 also shows a plot of total non-bonded interaction between fragments 5 and 7 indicating that it was more than $250 \%$ higher than between fragments 6 and 7. These interactions were observed to be attractive and electrostatic in nature, and the 
magnitude of these interactions was also much higher than individual kerogen fragments and clay interactions. Thus, attractive interactions between kerogen fragments hold the kerogen structure together.

\section{Conclusions}

In this work, the non-bonded interactions between the complete 3D kerogen structure and clay were studied using molecular dynamics simulation. The construction of the molecular model of 12-unit 3D kerogen was based on Siskin's 2-dimensional structure divided among seven fragments. Fragments 1, 2 and 3 consisted of aliphatic hydrocarbons (carbon-carbon single bond). In addition, fragment 3 consisted of aromatic hydrocarbon (one benzene ring) which was connected with aliphatic hydrocarbons. Fragment 4 consisted of aromatic and olefinic hydrocarbons and one Oxygen atom with high negative charge. Similarly, fragments 5, 6, and 7 comprised of aliphatic, olefinic, and aromatic hydrocarbons, aliphatic nitrogen, ammonical nitrogen, oxygen atoms, and these fragments were larger than other fragments. Additionally, fragments 6 and 7 had sulphur atoms. Oxygen and nitrogen atoms present in these fragments exhibited high negative charge, resulting in high non-bonded interaction energy. The representative 3D kerogen model was verified by developing PDFs on the 12-unit 3D kerogen model. On the other hand, the validation of clay model was accomplished by comparing dspacing of the clay structure from molecular dynamics simulations with the experimental result from XRD. Thus, merging these two models, the complex and robust kerogen-clay model was developed in our study. Our simulation results reveal that attractive non-bonded interactions between kerogen and clay were responsible for holding them together. The identification of the seven kerogen fragments and their orientations was studied in proximity to the clay surface. While the aliphatic hydrocarbons of fragment 1 and aromatic hydrocarbons of fragment 2 were attracted toward clay surface, fragments 3 and 4 were observed to be flat and parallel to the clay surface. The aromatic hydrocarbons of fragments 5 and 6 were normal to the clay surface. The aliphatic and aromatic hydrocarbons as well as the aromatic nitrogen atoms were observed to be shifted toward the clay surface, with flat orientations. Furthermore, the non-bonded energy between each of kerogen fragments and clay was computed. The computations indicate that the clay exhibits strong non-bonded interactions with kerogen fragments 4 through 7 . These nonbonded interactions were observed to be comparatively higher than interactions between clay and fragments 1 through 3 . Fragment 7 exhibited higher non-bonded interactions with clay than other 
fragments. These attractive interactions were found to be predominated by VDW energy. Similarly, the non-bonded interactions within kerogen fragments 4 through 7 have been studied. Fragments 5 and 6, fragments 5 and 7, and fragments 6 and 7 have strong attractive non-bonded interactions that were predominantly electrostatic in nature. These non-bonded interactions between specific kerogen fragments and between clay and kerogen fragments play an important role in understanding the existence and mechanisms of the kerogen-clay interlocking in the oil shale at the molecular level. The extent of the energy differences and also locations of the preferential and higher interactions is important for evaluation of kerogen extraction in future studies. This work provides insight for future research to develop new methods of extraction of the kerogen economically, efficiently, and environmental friendly from the oil shale.

\section{Acknowledgement}

The authors wish to acknowledge the support of Department of Energy National Nuclear Security Administration under grant \# DE-FG52-08NA28921. We would also acknowledge Computationally Assisted Science and Technology (CCAST) for providing computational resources at North Dakota State University. We also acknowledge support from Mountain Plains Consortium (MPC) Grant \#

\section{References}

[1] Guo H, Lin J, Yang Y, Liu Y. Effect of minerals on the self-heating retorting of oil shale: Selfheating effect and shale-oil production. Fuel 2014;118:186-93.

[2] Task Force on Strategic Unconventional Fuels. Development of America's strategic unconventional fuels resources. 2007.

[3] Alstadt KN, Katti DR, Katti KS. An in situ FTIR step-scan photoacoustic investigation of kerogen and minerals in oil shale. Spectrochimica Acta Part a-Molecular and Biomolecular Spectroscopy 2012;89:105-13.

[4] Miknis FP. Solid-state 13C NMR in oil shale research: an introduction with selected applications. Composition, Geochemistry and Conversion of Oil Shales: Springer; 1995. p. 69-91.

[5] Razvigorova M, Budinova T, Tsyntsarski B, Petrova B, Ekinci E, Atakul H. The composition of acids in bitumen and in products from saponification of kerogen: Investigation of their role as connecting kerogen and mineral matrix. International Journal of Coal Geology 2008;76:243-9.

[6] Brons G, Siskin M, Botto RI, Guven N. Quantitative mineral distribution in Green River and Rundle oil shales. Energy \& Fuels 1989;3:85-8.

[7] Yen TF, Chilingarian GV. Oil shale. 1976.

[8] Wu LM, Zhou CH, Keeling J, Tong DS, Yu WH. Towards an understanding of the role of clay minerals in crude oil formation, migration and accumulation. Earth-Science Reviews 2012;115:373-86. 
[9] Johns WD. CLAY MINERAL CATALYSIS AND PETROLEUM GENERATION. Annual Review of Earth and Planetary Sciences 1979;7:183-98.

[10] Tiwari P, Deo M, Lin CL, Miller JD. Characterization of oil shale pore structure before and after pyrolysis by using X-ray micro CT. Fuel 2013;107:547-54.

[11] Na JG, Im CH, Chung SH, Lee KB. Effect of oil shale retorting temperature on shale oil yield and properties. Fuel 2012;95:131-5.

[12] Liu X, Zhan J-H, Lai D, Liu X, Zhang Z, Xu G. Initial Pyrolysis Mechanism of Oil Shale Kerogen with Reactive Molecular Dynamics Simulation. Energy \& Fuels 2015;29:2987-97.

[13] Bauman JH, Deo M. Simulation of a Conceptualized Combined Pyrolysis, In Situ Combustion, and CO2 Storage Strategy for Fuel Production from Green River Oil Shale. Energy \& Fuels 2012;26:1731-9.

[14] Amarasinghe PM, Katti KS, Katti DR. Nature of organic fluid-montmorillonite interactions: An FTIR spectroscopic study. Journal of Colloid and Interface Science 2009;337:97-105.

[15] Amarasinghe PM, Katti KS, Katti DR. Insight into Role of Clay-Fluid Molecular Interactions on Permeability and Consolidation Behavior of Na-Montmorillonite Swelling Clay. Journal of Geotechnical and Geoenvironmental Engineering 2012;138:138-46.

[16] Katti DR, Patwary ZR, Katti KS. Modelling clay-fluid interactions in montmorillonite clays. Environmental Geotechnics 2016.

[17] Katti DR, Srinivasamurthy L, Katti KS. Molecular modeling of initiation of interlayer swelling in Na-montmorillonite expansive clay. Canadian Geotechnical Journal 2015;52:1385-95.

[18] Pradhan SM, Katti KS, Katti DR. Evolution of Molecular Interactions in the Interlayer of NaMontmorillonite Swelling Clay with Increasing Hydration. International Journal of Geomechanics 2015;15.

[19] Katti DR, Schmidt SR, Ghosh P, Katti KS. Modeling the response of pyrophyllite interlayer to applied stress using steered molecular dynamics. Clays and Clay Minerals 2005;53:171-8.

[20] Pradhan SM, Katti KS, Katti DR. Evolution of Molecular Interactions in the Interlayer of NaMontmorillonite Swelling Clay with Increasing Hydration. International Journal of Geomechanics 2015;15:04014073.

[21] Sikdar D, Pradhan SM, Katti DR, Katti KS, Mohanty B. Altered phase model for polymer clay nanocomposites. Langmuir 2008;24:5599-607.

[22] Pradhan SM, Katti DR, Katti KS. Steered molecular dynamics study of mechanical response of full length and short collagen molecules. Journal of Nanomechanics and Micromechanics 2011;1:104-10.

[23] Ghosh P, Katti DR, Katti KS. Mineral proximity influences mechanical response of proteins in biological mineral-protein hybrid systems. Biomacromolecules 2007;8:851-6.

[24] Ghosh P, Katti DR, Katti KS. Mineral and protein-bound water and latching action control mechanical behavior at protein-mineral interfaces in biological nanocomposites. Journal of Nanomaterials 2008.

[25] Katti DR, Pradhan SM, Katti KS. Directional dependence of hydroxyapatite-collagen interactions on mechanics of collagen. Journal of Biomechanics 2010;43:1723-30.

[26] Pradhan SM, Katti KS, Katti DR. Multiscale Model of Collagen Fibril in Bone: Elastic Response. Journal of Engineering Mechanics 2014;140:454-61.

[27] Sharma A, Payne S, Katti KS, Katti DR. Evaluating Molecular Interactions in PolycaprolactoneBiomineralized Hydroxyapatite Nanocomposites using Steered Molecular Dynamics. Jom 2015;67:73343.

[28] Ahmadov R, Vanorio T, Mavko G. Confocal laser scanning and atomic-force microscopy in estimation of elastic properties of the organic-rich Bazhenov Formation. The Leading Edge 2009;28:1823.

[29] Alstadt KN, Katti KS, Katti DR. Nanoscale Morphology of Kerogen and in Situ Nanomechanical Properties of Green River Oil Shale. Journal of Nanomechanics and Micromechanics 2016;6:04015003. 
[30] Kelemen SR, Siskin M, Kwiatek PJ, Walters CC. FUEL 172-Evaluation of XPS for analysis of nitrogen and sulfur forms in oil shale. Abstracts of Papers of the American Chemical Society 2008;235.

[31] Siskin M, Brons G, Payack JF. DISRUPTION OF KEROGEN MINERAL INTERACTIONS IN OIL SHALES. Energy \& Fuels 1987;1:248-52.

[32] Katti DR, Upadhyay HB, Katti KS. Molecular interactions of kerogen moieties with Namontmorillonite: An experimental and modeling study. Fuel 2014;130:34-45.

[33] Wu T, Xue Q, Li X, Tao Y, Jin Y, Ling C, et al. Extraction of kerogen from oil shale with supercritical carbon dioxide: Molecular dynamics simulations. The Journal of Supercritical Fluids 2015.

[34] Ibrahimov RA, Bissada KK. Comparative analysis and geological significance of kerogen isolated using open-system (palynological) versus chemically and volumetrically conservative closed-system methods. Organic Geochemistry 2010;41:800-11.

[35] Siskin M, Scouten CG, Rose KD, Aczel T, Colgrove SG, Pabst Jr RE. Detailed structural characterization of the organic material in Rundle Ramsay Crossing and Green River oil shales. Composition, geochemistry and conversion of oil shales: Springer; 1995. p. 143-58.

[36] Orendt AM, Pimienta ISO, Badu SR, Solum MS, Pugmire RJ, Facelli JC, et al. Three-Dimensional Structure of the Siskin Green River Oil Shale Kerogen Model: A Comparison between Calculated and Observed Properties. Energy \& Fuels 2013;27:702-10.

[37] Faulon JL, Vandenbroucke M, Drappier JM, Behar F, Romero M. 3D CHEMICAL-MODEL FOR GEOLOGICAL MACROMOLECULES. Organic Geochemistry 1990;16:981-\&.

[38] Skipper NT, Sposito G, Chang FRC. MONTE-CARLO SIMULATION OF INTERLAYER MOLECULARSTRUCTURE IN SWELLING CLAY-MINERALS .2. MONOLAYER HYDRATES. Clays and Clay Minerals 1995;43:294-303.

[39] Teppen BJ, Rasmussen K, Bertsch PM, Miller DM, Schafer L. Molecular dynamics modeling of clay minerals .1. Gibbsite, kaolinite, pyrophyllite, and beidellite. Journal of Physical Chemistry B 1997;101:1579-87.

[40] Schmidt SR, Katti DR, Ghosh P, Katti KS. Evolution of mechanical response of sodium montmorillonite interlayer with increasing hydration by molecular dynamics. Langmuir 2005;21:806976.

[41] Sikdar D, Katti DR, Katti KS. A molecular model for epsilon-caprolactam-based intercalated polymer clay nanocomposite: Integrating modeling and experiments. Langmuir 2006;22:7738-47.

[42] Vanommeslaeghe K, Hatcher E, Acharya C, Kundu S, Zhong S, Shim J, et al. CHARMM General Force Field: A Force Field for Drug-Like Molecules Compatible with the CHARMM All-Atom Additive Biological Force Fields. Journal of Computational Chemistry 2010;31:671-90.

[43] Kirkpatrick S, Gelatt CD, Vecchi MP. OPTIMIZATION BY SIMULATED ANNEALING. Science 1983;220:671-80.

[44] Brooks SP, Morgan BJT. OPTIMIZATION USING SIMULATED ANNEALING. Statistician 1995;44:241-57. 


\section{FIGURE CAPTIONS}

Figure 1. Molecular model of Dry Sodium (Na)-Montmorillonite.

Figure 2. Molecular structure of kerogen based on Siskin's structure a) fragment 1, b) fragment 2, c) fragment 3 , d) fragment 4 , e) fragment 5 , f) fragment 6 , and g) fragment 7.

Figure 3. Molecular model of three-dimensional Green River Type I kerogen. The chemical formula is $\mathrm{C}_{645} \mathrm{H}_{1017} \mathrm{~N}_{19} \mathrm{O}_{17} \mathrm{~S}_{4}$. Color coding: $\mathrm{C}$ (cyan), $\mathrm{H}$ (white), $\mathrm{N}$ (blue), $\mathrm{O}$ (red), and $\mathrm{S}$ (orange).

Figure 4. 12-unit three-dimensional kerogen model.

Figure 5. Initial 12-unit three-dimensional kerogen and 6x3 unit Na-montmorillonite clay model showing kerogen within clay mineral matrix.

Figure 6. Plot of total energy versus time from minimization to $5 \mathrm{~ns}$. Plot shows the equilibration of 12 unit kerogen and Na-montmorillonite clay model in MD simulation.

Figure 7. Structure of representative model of Na-montmorillonite at $300 \mathrm{~K}$ temperature and 1 atmospheric pressure (d-spacing $=10.72 \AA)$.

Figure 8. 12-unit three dimensional molecular model of kerogen after equilibrium.

Figure 9. A Pairwise Distribution Function (PDF) plot of 12-unit kerogen model at time period of $1 \mathrm{~ns}$.

Figure 10. Kerogen-clay model after the simulation up to $5 \mathrm{~ns}$.

Figure 11. Snapshot showing the conformation of different fragments of kerogen in close proximity to clay models a) fragment 1, b) fragment 2 , c) fragment 3 , d) fragment 4 , e) fragment 5 , and f) fragment 6 . Only certain numbers of individual fragment are close to clay surface represented by Licorice form.

Figure 12. The conformation of kerogen fragment 7 in close proximity to clay surface. 
Figure 13. Overall interaction energy of 12-unit 3D kerogen with clay.

Figure 14. The interaction energy between sodium $(\mathrm{Na})$ cations and clay sheets before and after the introduction of kerogen.

Figure 15. Interaction energy of clay with seven fragments of kerogen, fragment 1 , fragment 2 , fragment 3 , fragment 4 , fragment 5 , fragment 6 , and fragment 7 , in close proximity to clay surface.

Figure 16. Attractive interactions between kerogen fragments: fragments 4 and 5, fragments 4 and 6 , fragments 4 and 7, fragments 5 and 6 , fragments 5 and 7 , and fragments 6 and 7 . 

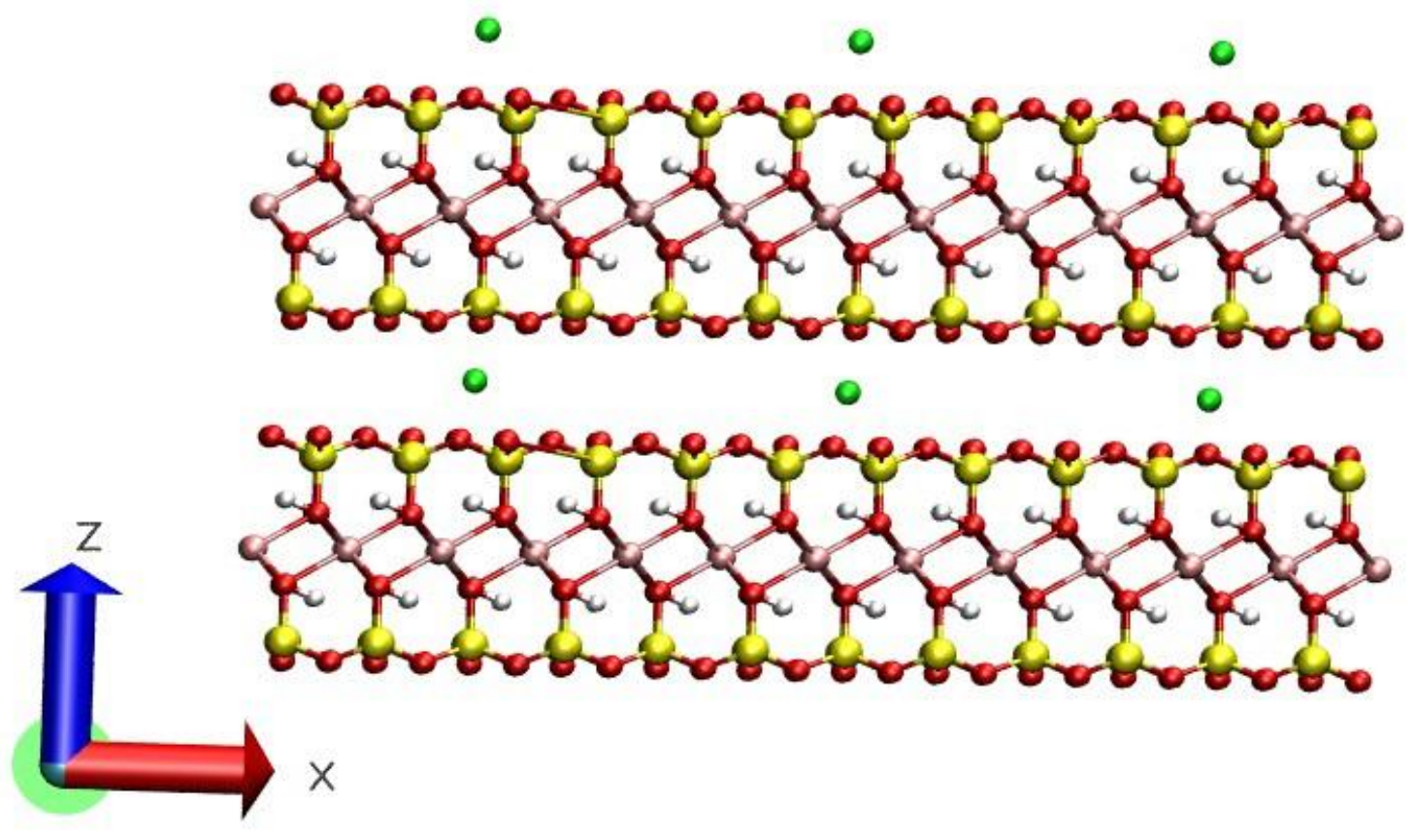

(a)
(b)
(c)
(d)

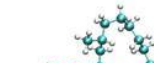
La $^{2}$
$\underset{\rightarrow}{\rightarrow}$
$\rightarrow$ I.
o
(e)
(f)

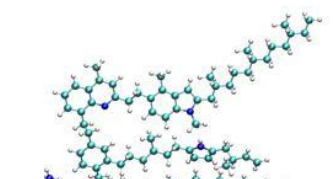
(g)

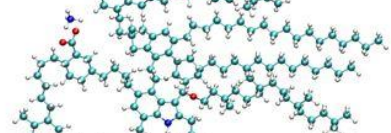
$c$
0

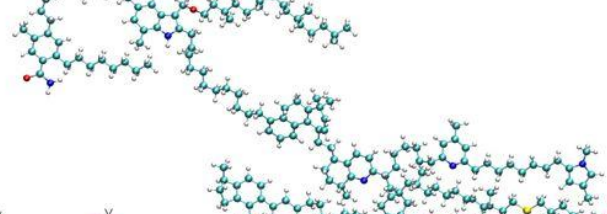
$\stackrel{y}{\longrightarrow}$

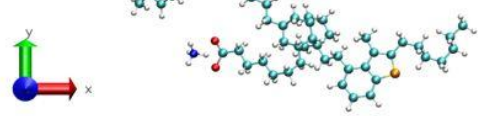
II $\Rightarrow$ a 


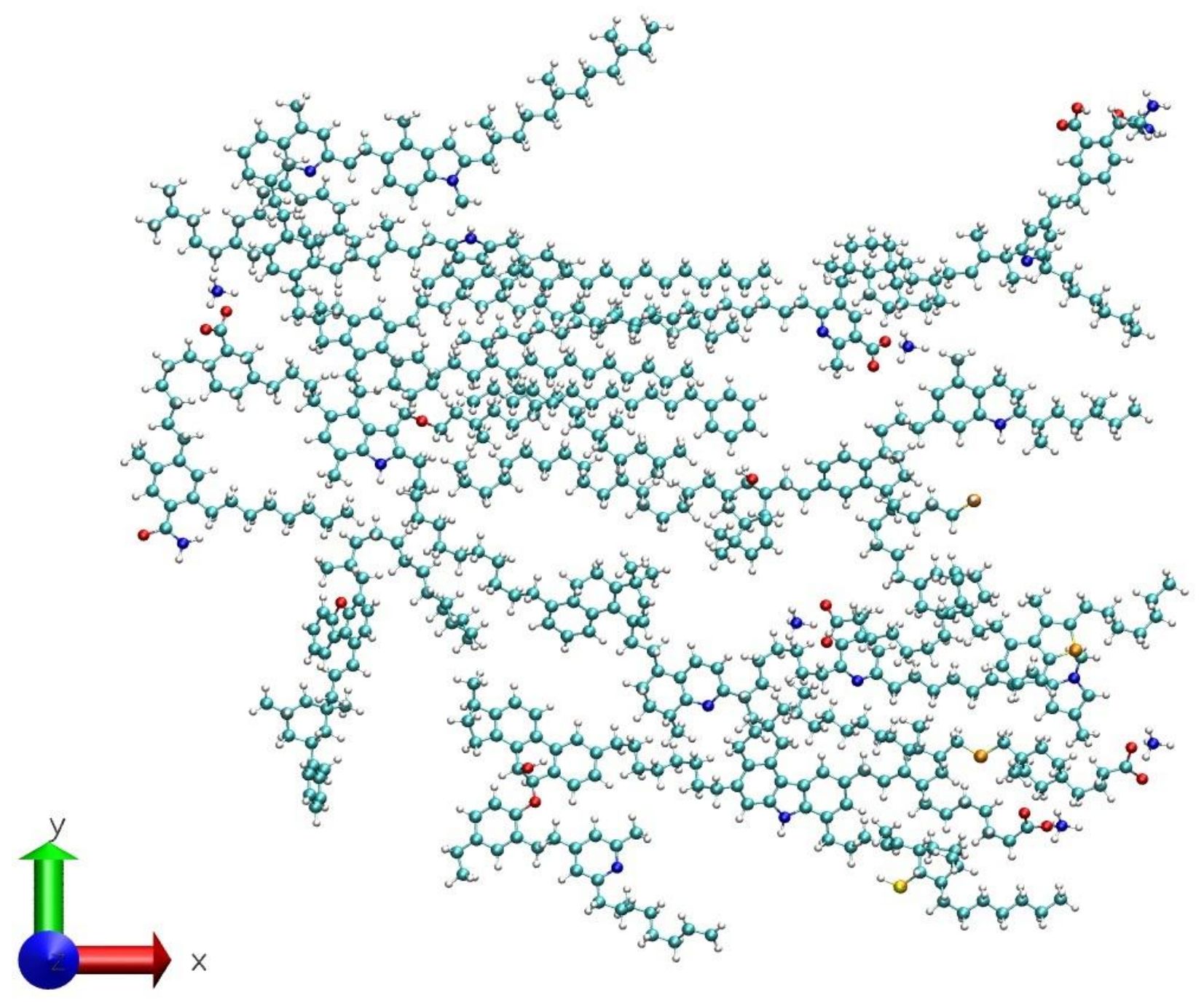




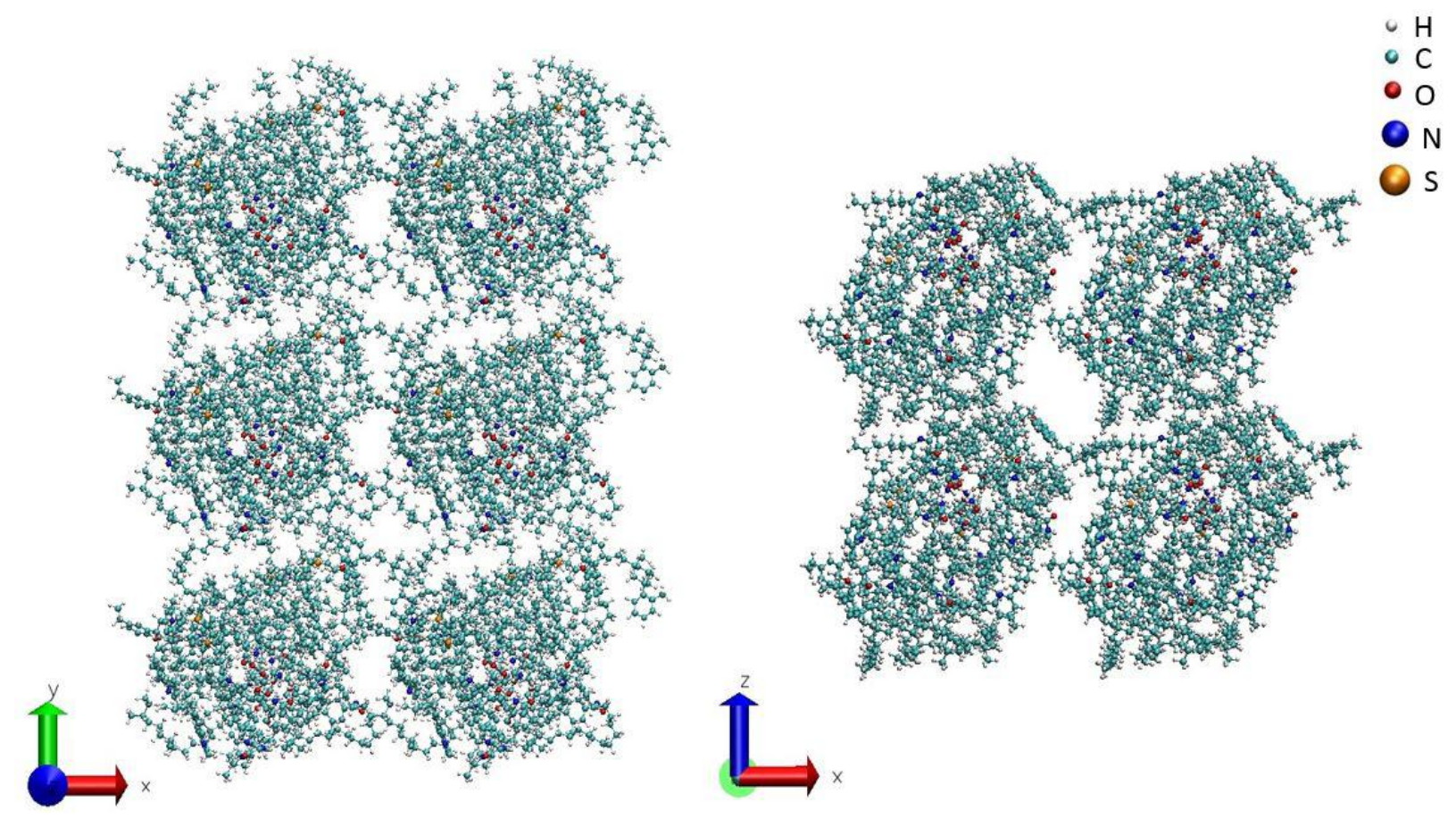




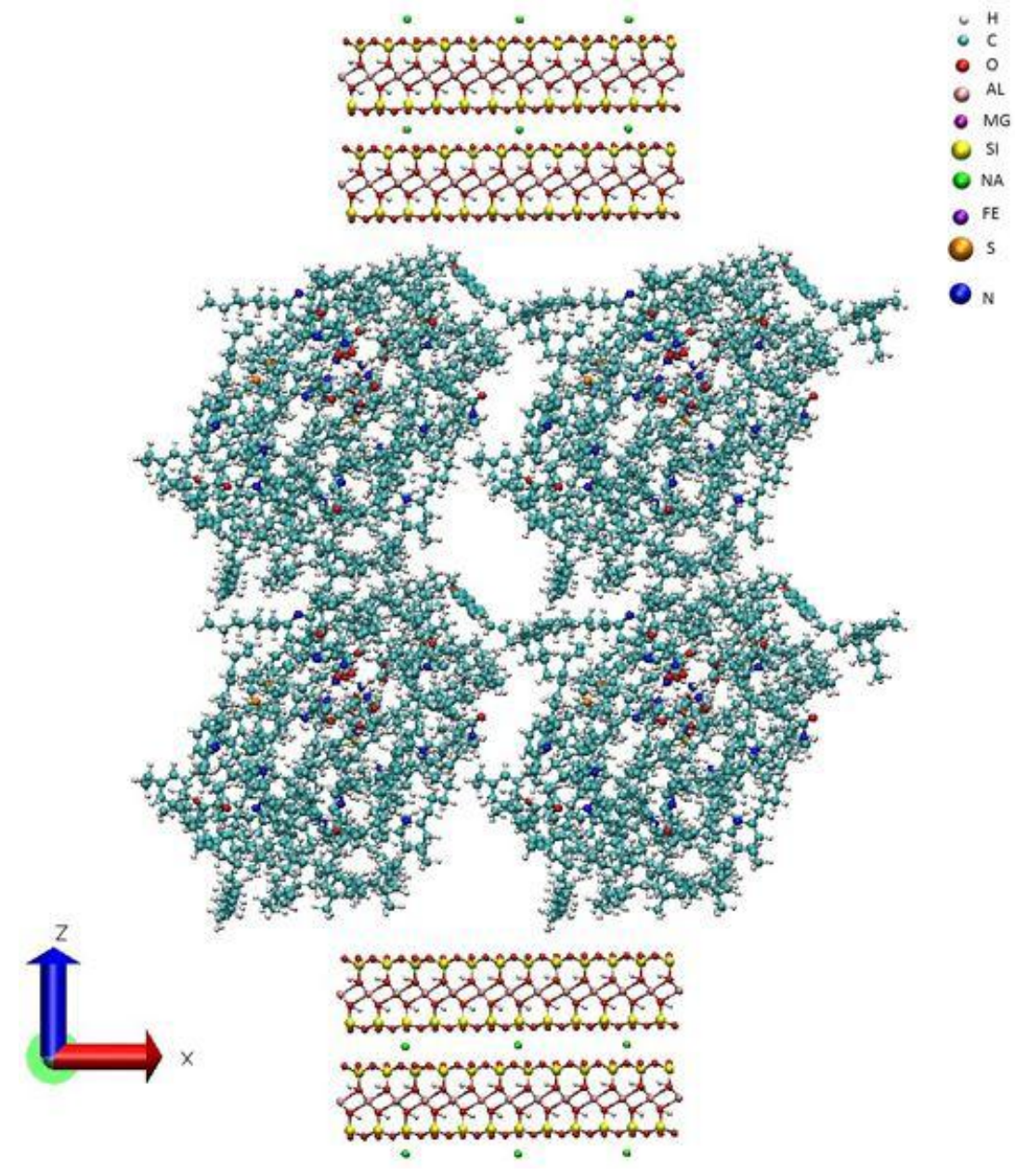




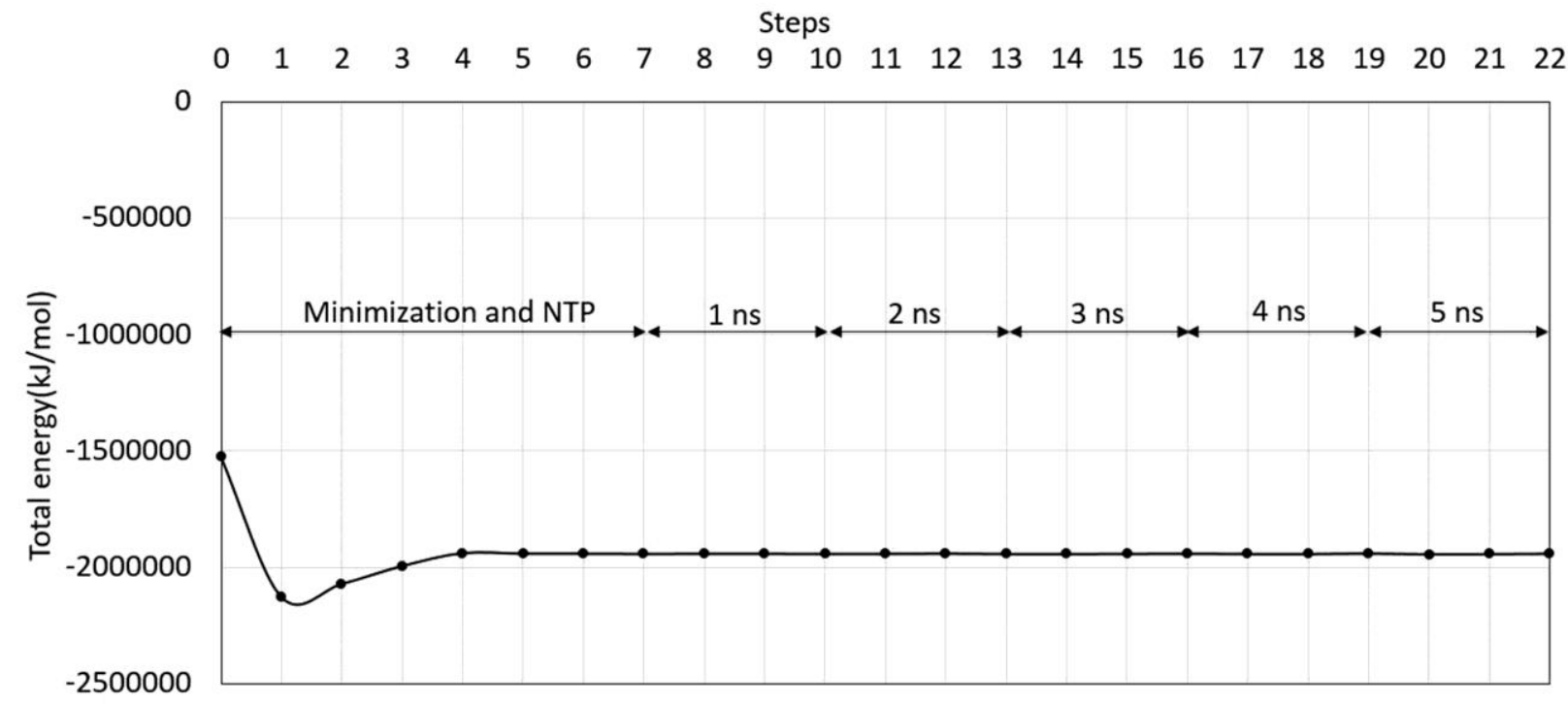




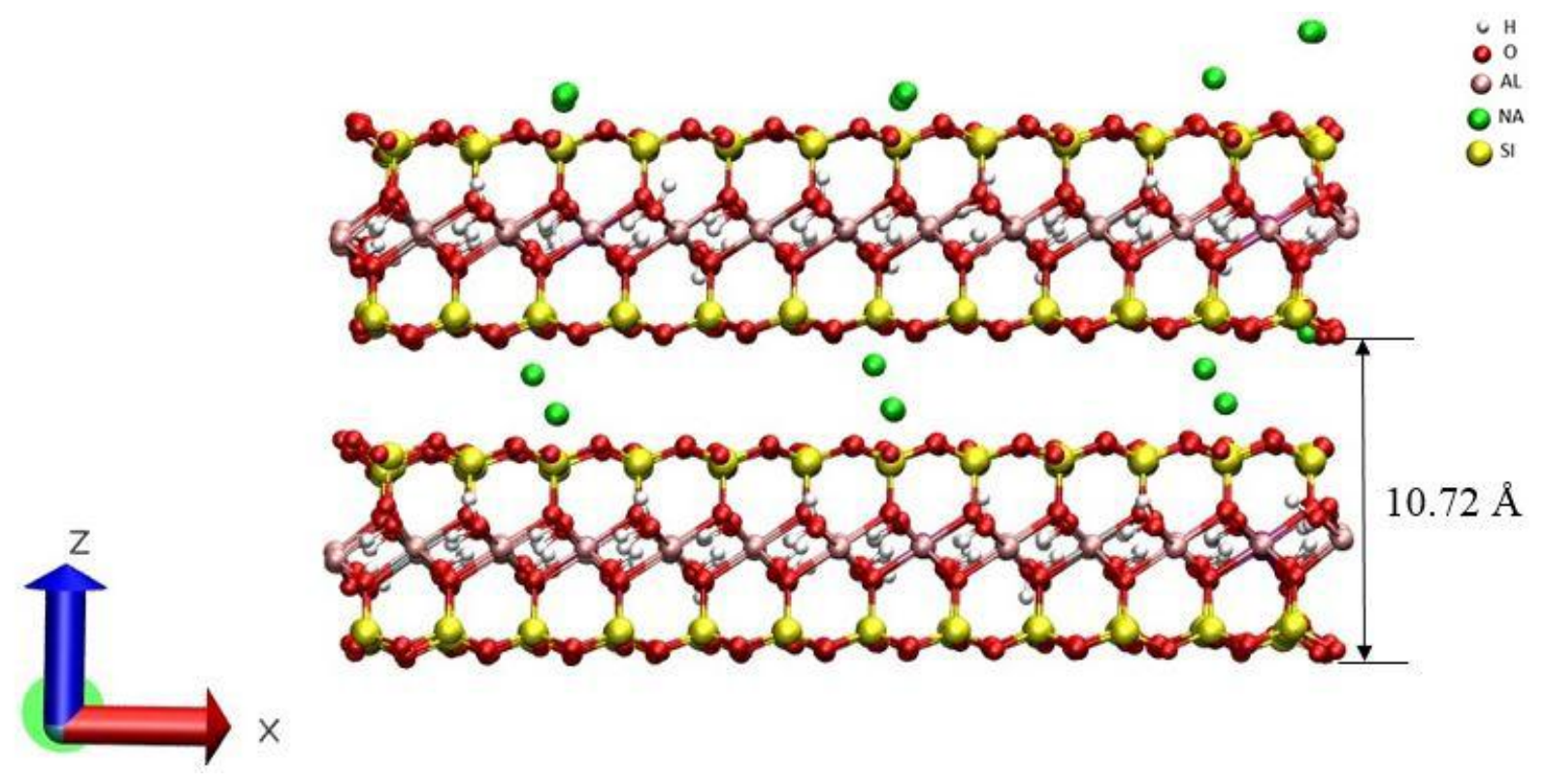




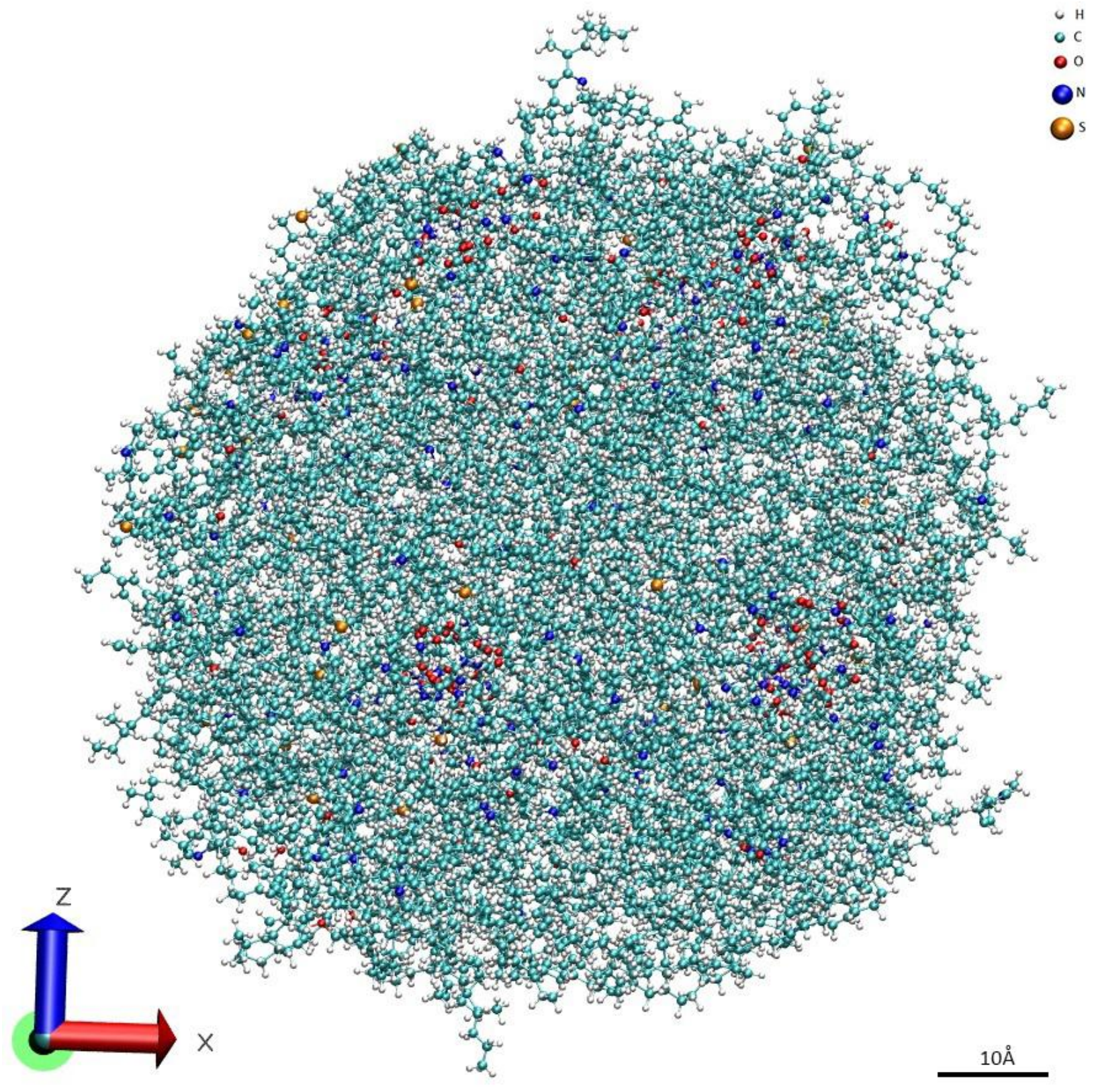




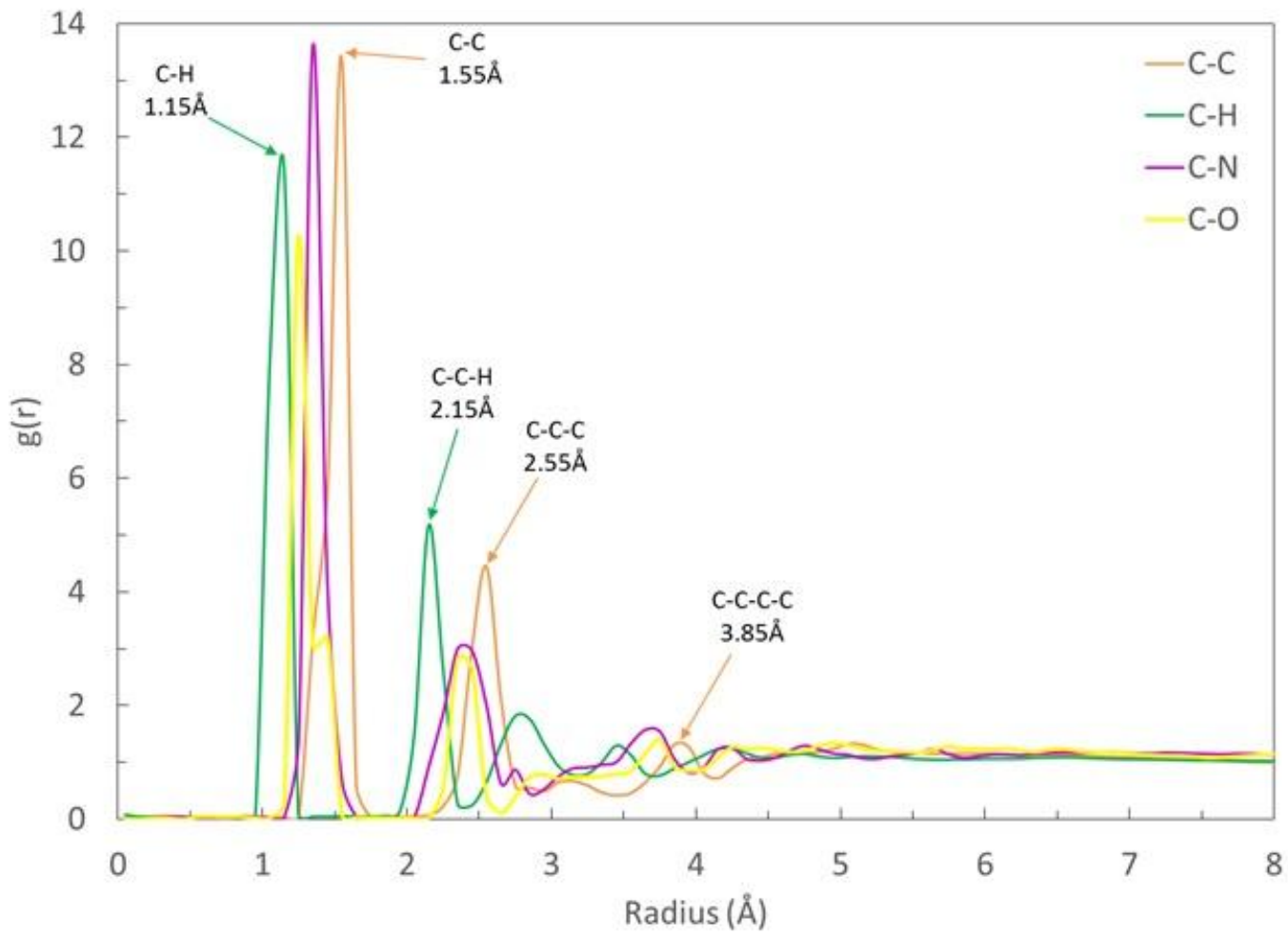




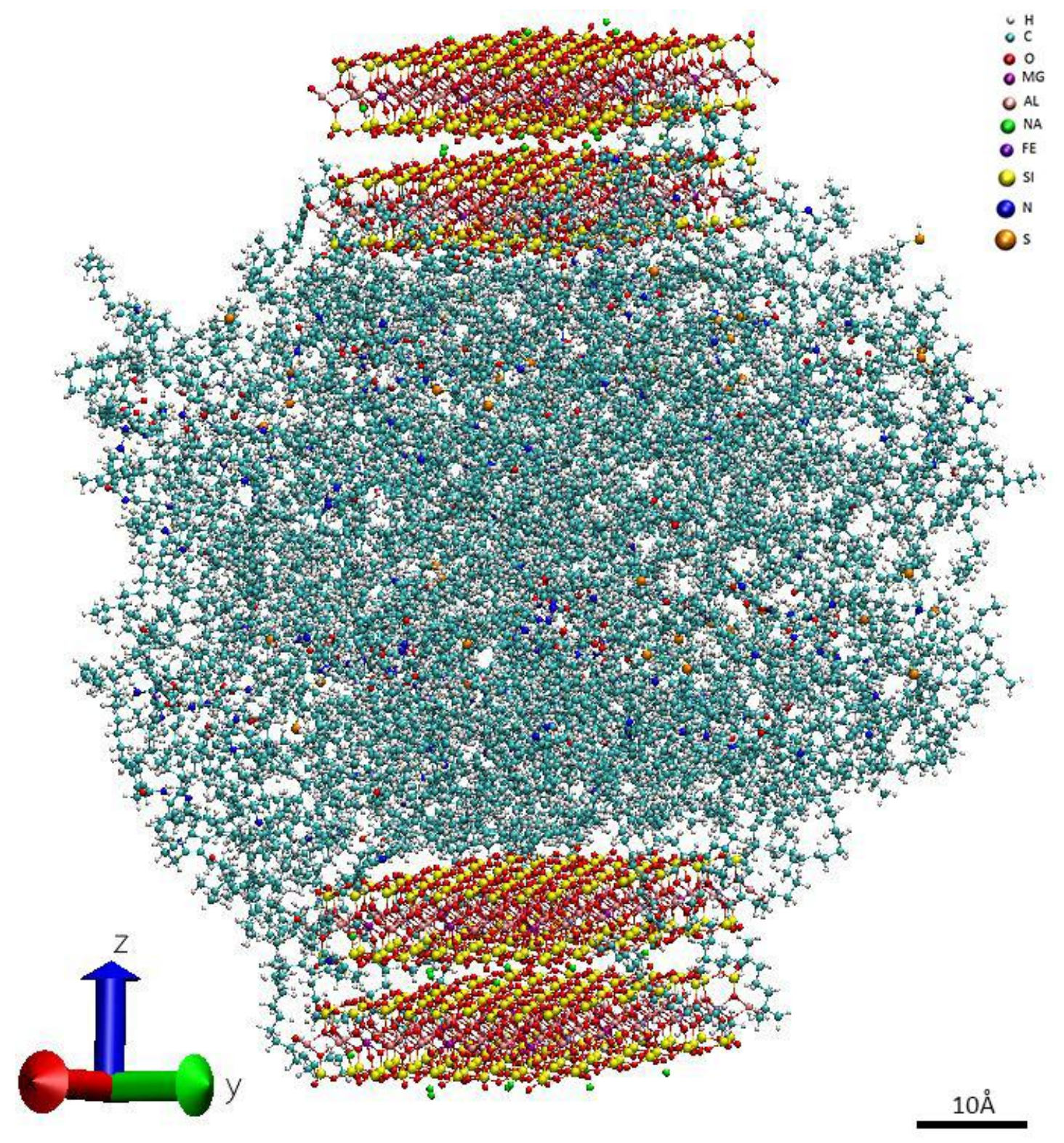


(a)

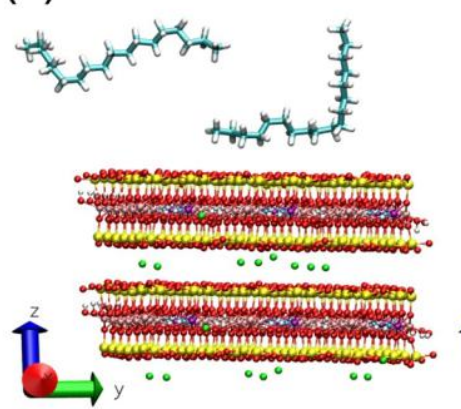

(d)

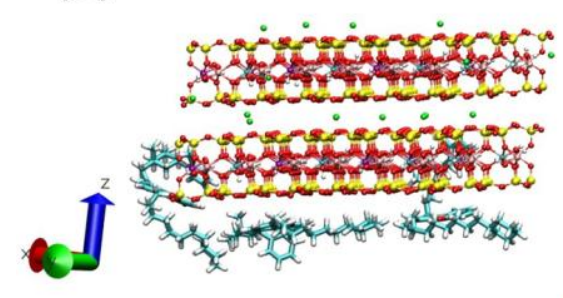

(b)

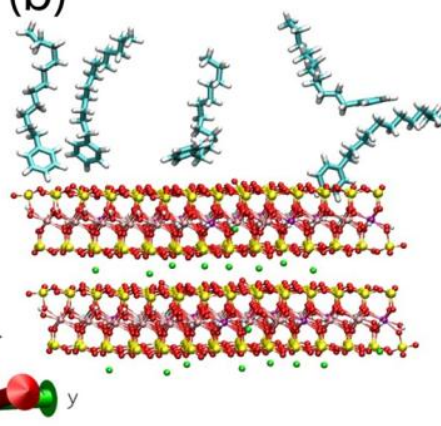

(e)

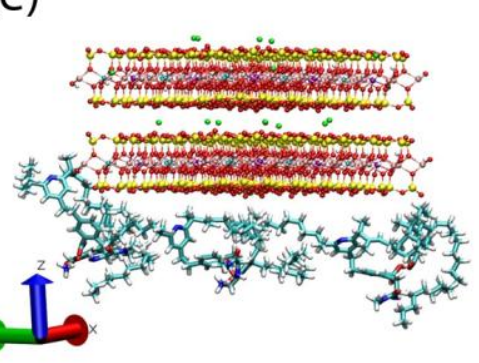

(c)

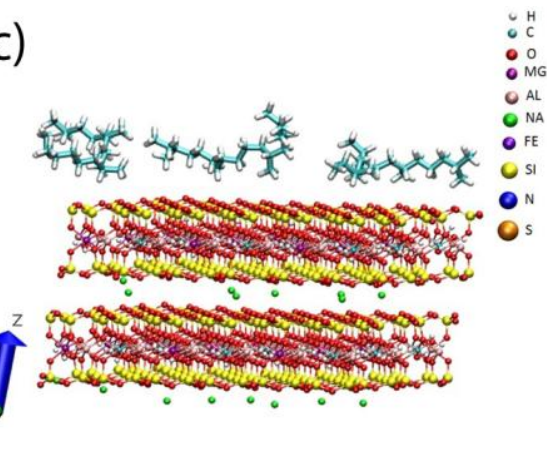

(f)

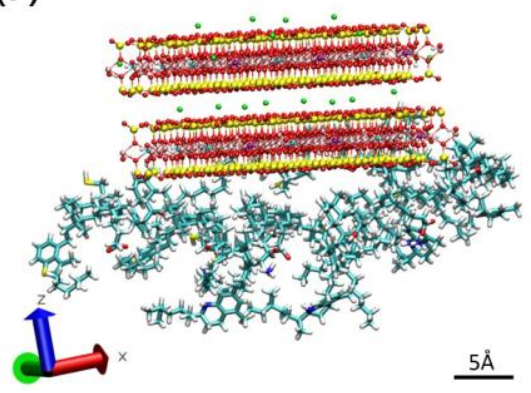




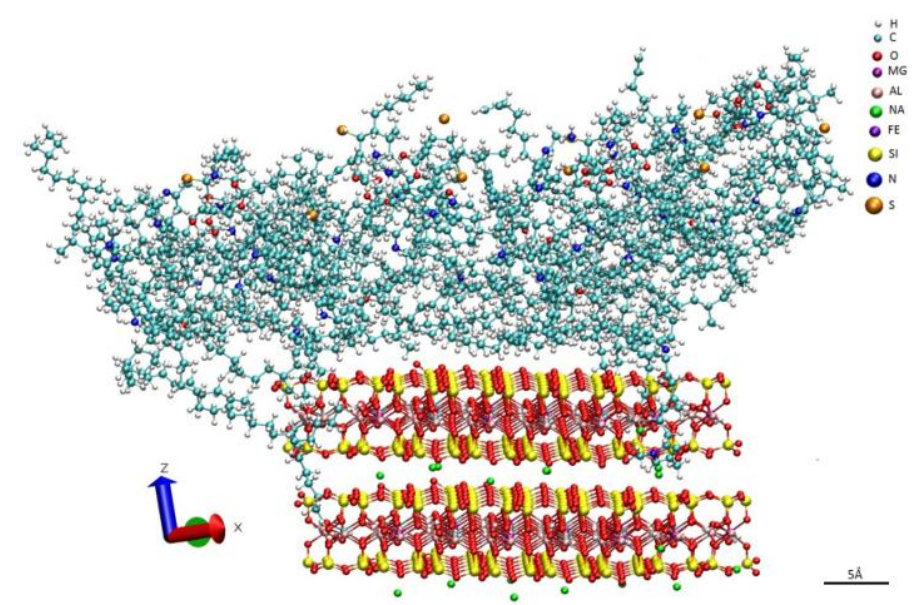




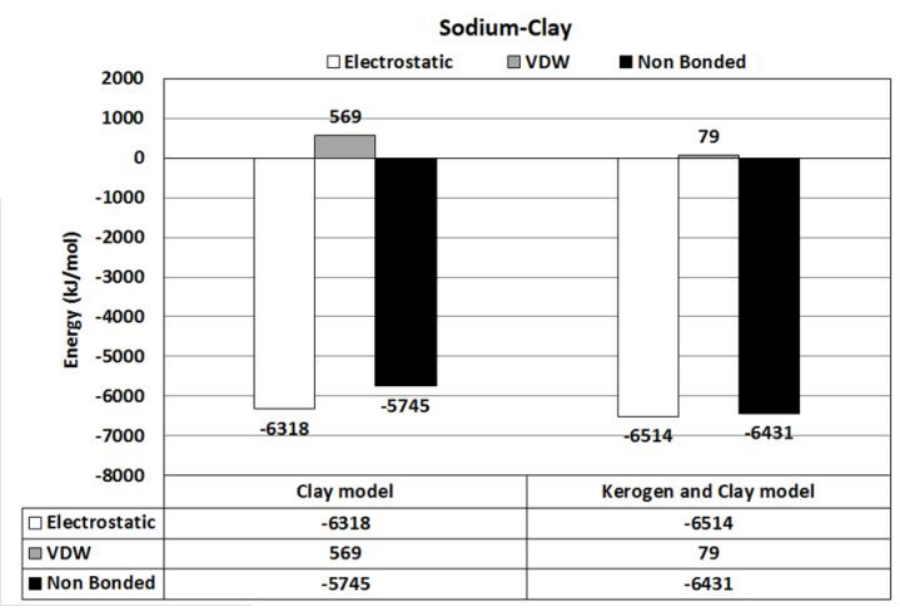




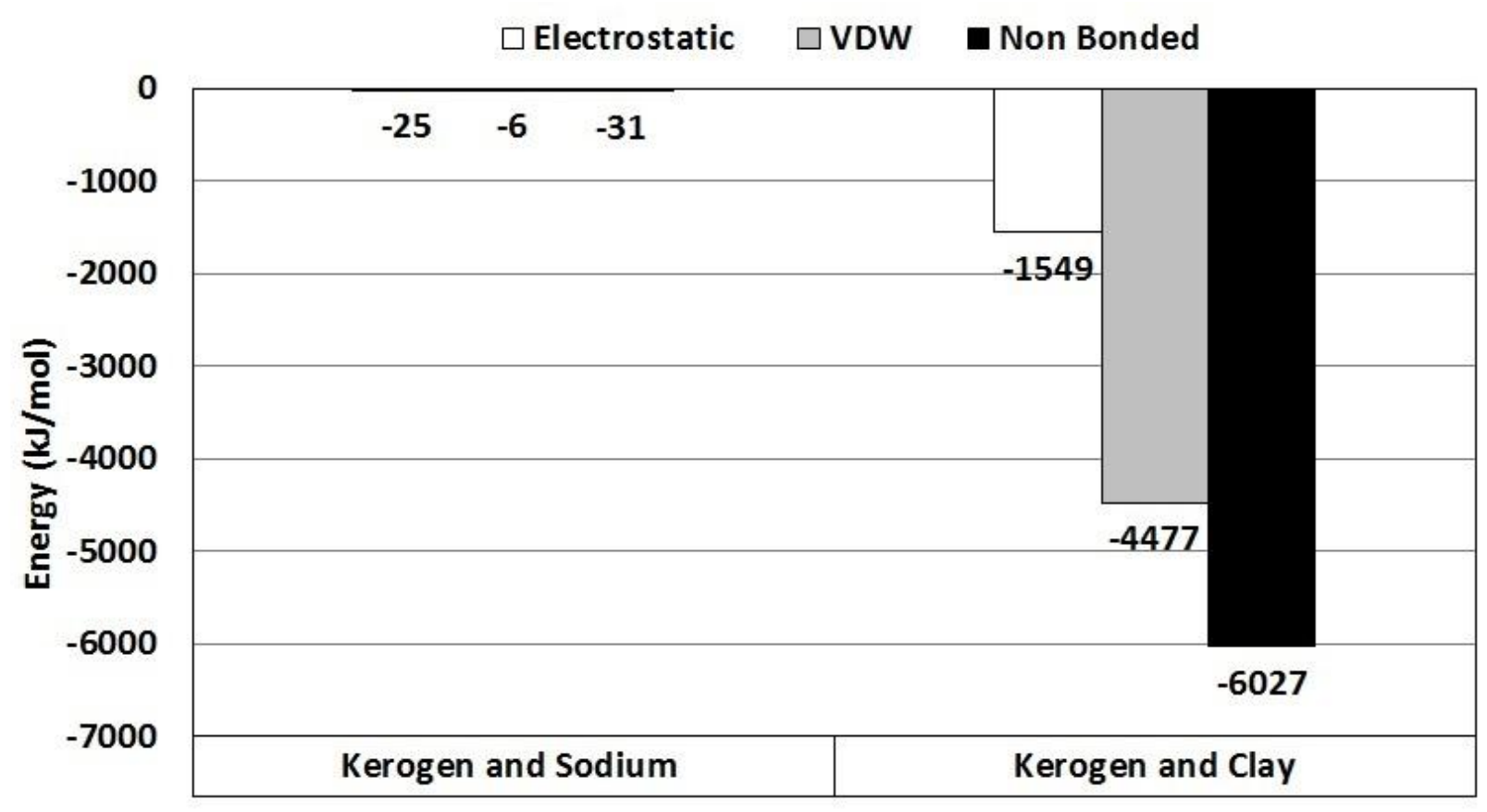




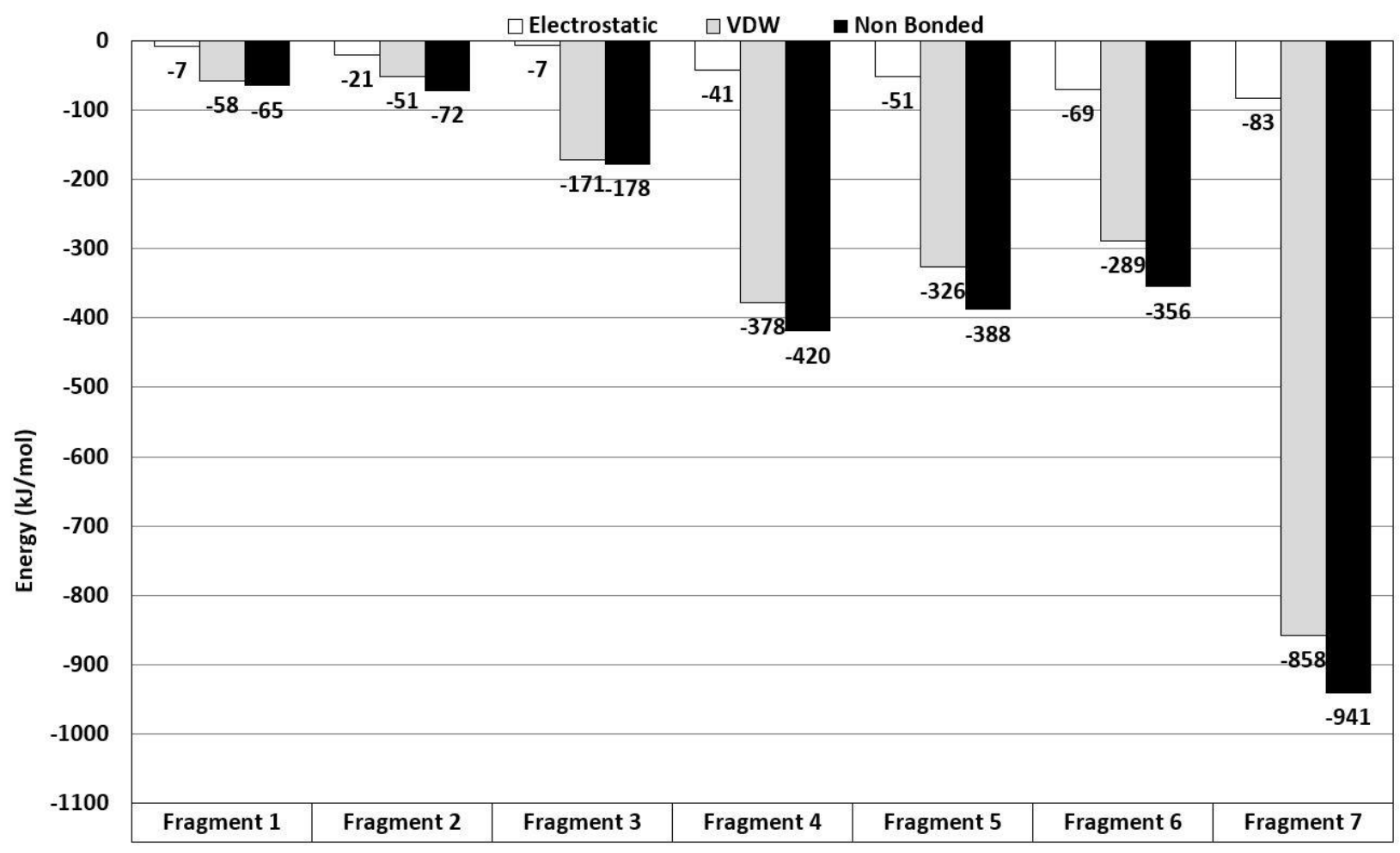




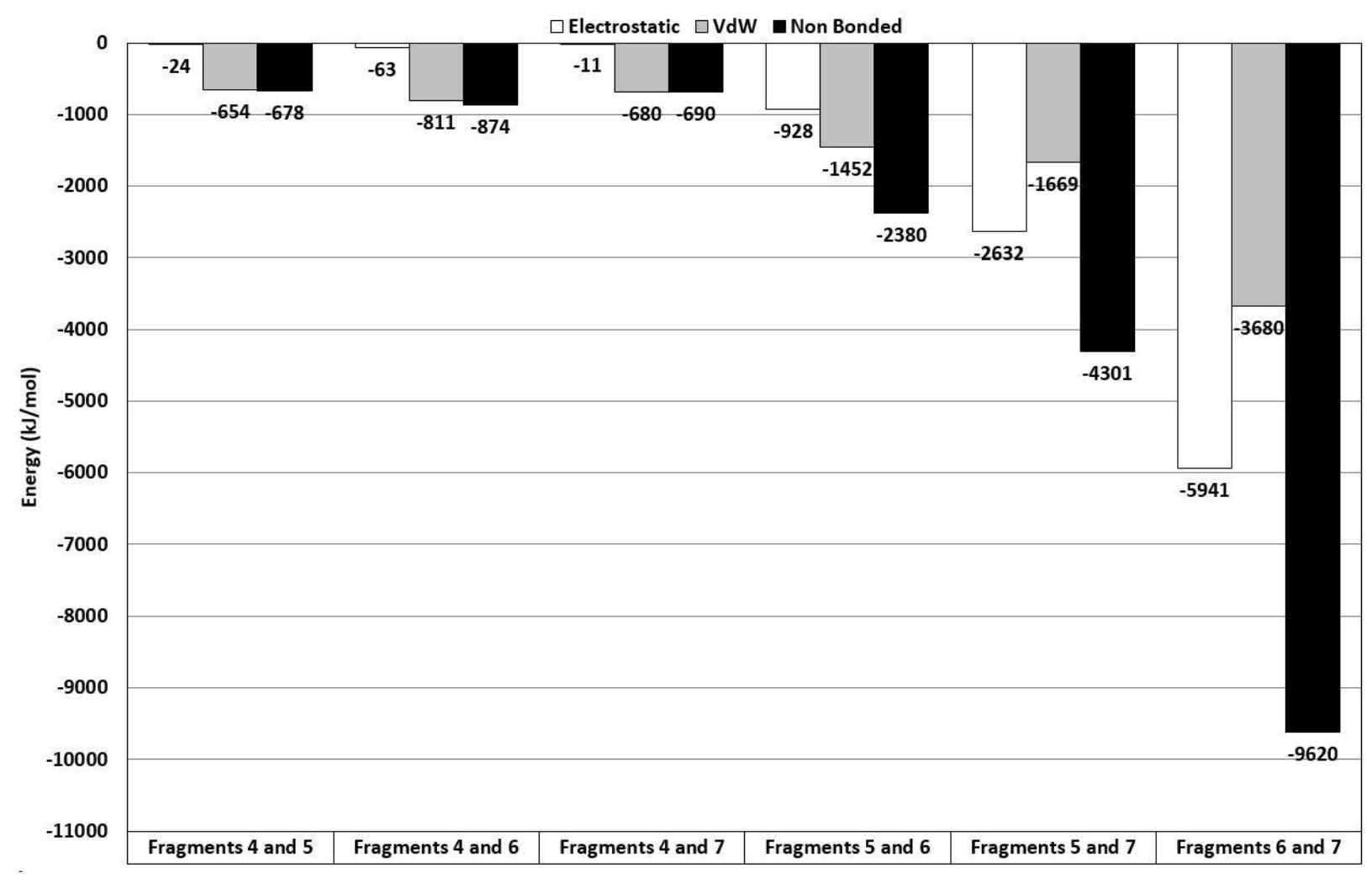

